\title{
Iluminando sombras
}

\author{
Aproximaciones y \\ experiencias para un \\ patrimonio accesible
}

Lighting shadows

Approaches and experiences for accessible heritage

\section{Resumen}

Autores:

José Ignacio Stang josestang@conicet.gov.ar

Agustina Pezza agustinapezza@gmail.com

CIECS (CONICET y UNC)

Argentina

Recibido: 16 Abr 2018 Aceptado: 16 Ene 2019
L a investigación lluminando sombras busca brindar a personas con discapacidad visual los recursos necesarios para que, en el transcurso de una visita a un edificio del patrimonio edificado de la ciudad de Córdoba, Argentina, puedan imaginar cómo es la realidad que tienen de frente y que los contiene, aspirando a que cada uno gestione su propio recorrido. El presente trabajo expone reflexiones teóricas y metodológicas al respecto, y los resultados de aplicación luego de una primera experiencia de visita. En un carácter cualitativo, el enfoque elegido como modalidad metodológica es el Estudio-Acción, lo que supone una epistemología y una perspectiva nosológica especial. Se adoptó, además, una perspectiva y lógica experiencial de conservación activa, donde el objetivo es el enriquecimiento de la memoria colectiva, el reconocimiento de su autenticidad y sus valores cambiantes, y su apropiación por la comunidad.

Palabras clave: patrimonio edificado, discapacidad visual, accesibilidad, recorrido vivencial, participación.

\section{Abstract:}

The investigation Illuminating Shadows seeks to provide people with visual disabilities with the necessary resources so that, during a visit to a building of the built heritage of the city of Cordoba, Argentina, they can imagine what the reality that they have in front of them is like and what it contains, aspiring to have each one manage their own route. This paper presents theoretical and methodological reflections on this subject, and the results of their application after a first visit experience. In a qualitative sense, the approach chosen as a methodological modality is Study-Action, which implies a special epistemology and nosological perspective. In addition, a perspective and experiential logic of active conservation was adopted, where the objective is the enrichment of the collective memory, the recognition of its authenticity and changing values, and its appropriation by the community.

Keywords: built heritage, visual disability, accessibility, experiential walk, participation 


\section{Introducción}

El patrimonio, adjetivado como cultural y al que se referirá particularmente desde la categoría de edificado, está inserto dentro de lo histórico. En cada comunidad los bienes reconocidos como patrimonio cultural identifican y caracterizan a una sociedad, explican su trayectoria histórica y le permiten la posibilidad de proyectarse a futuro. Tiene múltiples formas y expresiones que se muestran y ocultan, que provocan variadas vibraciones en la comunidad que interactúa y se relaciona de manera constante con tal realidad, siempre distinta, pero de la que es parte ineludible y a la que percibe y asume como puede o quiere.

La construcción del concepto de patrimonio cultural se realiza fundamentalmente a partir de un complejo proceso de atribuciones y valores. Atravesado por modas, junto al propio dinamismo de la sociedad, genera un relativismo en donde las personas interaccionamos de manera distinta con los bienes culturales. Tal condición favorece su protección en algunos casos, así como también el desentendimiento de su cuidado en otros. Dicha relación entre comunidad y patrimonio edificado se realiza de manera condicionada a partir de las propias particularidades que cada persona posea. Si dicha circunstancia se condiciona por una discapacidad visual, se suma el hecho de no poder establecer (persona-edificio) una relación visual. Como consecuencia de tal condición, pareciera cerrarse toda posibilidad de accesibilidad, contacto y vinculación, o al menos, si existiera alguna, podría quedar peligrosamente reducida solo al relato. El resultado de esta ausencia genera una autoexclusión. Frente a la condición de los objetos edificados y materializados, el desafío de poder derribar la barrera persona-edificio propone considerar necesariamente la accesibilidad $^{1}$ a ellos.

A partir de estas aproximaciones, el presente trabajo expone los primeros avances de la investigación en curso denominada lluminando sombras, ${ }^{2}$ que busca brindarle a personas con discapacidad visual los recursos necesarios para que, en el transcurso de una visita a un edificio del patrimonio edificado de la ciudad de Córdoba, Argentina, puedan imaginar cómo es la realidad

1 Considerada en su acepción más amplia, lo que significa no solo la eliminación de barreras físicas, sino que implica, además, una serie de principios como el uso universal, la flexibilidad en la forma de uso, el uso simple e intuitivo, entre otros.

2 Proyecto de investigación desarrollado desde e programa Estudios sobre los lugares del habitar y de la memoria, (habitarymemoria.wordpress.com) perteneciente al Centro de Investigaciones y Estudios sobre Cultura y Sociedad (CIECS, CONICET y UNC). que tienen de frente y que los contiene, aspirando a que cada uno gestione su propio recorrido. La experiencia que se presentará fue propuesta para un determinado grupo de personas en un edificio en particular. No obstante, se considera a futuro la posibilidad de generar nuevas iniciativas para otros grupos de visitantes con diferentes discapacidades, para el público en general, así como también el desarrollo en otros edificios de Córdoba.

Es una investigación de carácter cualitativo que como modalidad metodológica propone el Estudio-Acción, desde un enfoque y lógica experiencial de conservación activa. El objetivo es el enriquecimiento de la memoria colectiva, el reconocimiento de su autenticidad y sus valores cambiantes, y su apropiación por la comunidad.

Estructuralmente el trabajo presenta, en primera instancia, una posible mirada sobre la relación patrimonio-visitante y la particularidad de este vínculo en aquellas personas en condición de alguna discapacidad visual. Seguidamente se expone la descripción sobre la primera experiencia de visita desarrollada, relatando las estrategias y acciones llevadas a cabo, así como también los resultados obtenidos. Finalmente se presentan las conclusiones al respecto. El objetivo central es plantear la problemática respecto de la relación patrimonio-visitante, atendiendo a las posibles consecuencias que de tal relación puedan resultar.

\section{Sobre la relación}

\section{patrimonio-visitante}

Lo material arquitectónico urbano que nos rodea a diario (en especial aquello edificado y devenido luego en patrimonio) permite recuperar algo de los sucesos pasados e intangibles, al volverse un espacio donde es posible leer el tiempo transcurrido, ya que en el espacio leemos el tiempo (Schlögel, 2007). El espacio físico, por lo tanto, hace de eje entre lo mental e histórico. Esta relación material-inmaterial se muestra como un puente en el que se pueden trazar los objetos edificados en relación a los espacios urbanos.

La expresión del pasado a través de las diversas capas de la memoria en los bienes edificados, se significan en la generación de un escenario de sentidos múltiples y convierten a la ciudad en un ámbito de creación de formas significativas, lo que permite pensar en una dimensión estética de la ciudad (Liendivit, 2009) que, al proponer un acento sobre la sensibilidad perceptual, requiere de otras habilidades interpretativas y evocativas, puesto que "(...) ver no es creer, sino interpretar" (Mirzoeff, 2016, p.34). Las ciudades, por lo tanto, son hoy depositarias de valores culturales materiales e inmateriales, en donde dicho conjunto puede ser puesto al servicio de objetivos 
diversos (Coma Quintana y Santacana I Mestre, 2010) razón por la cual el conocimiento resulta imprescindible, así como lo es también ofrecer un acceso a este de manera ágil, clara y permanente.

Si a lo anterior se suma, además, la comprensión de que la realidad se compone de dos cosas, objetos y fenómenos (Wagensberg, 2005), al abordar el estudio de un edificio y sus espacios se debiera también observar más allá de la representación física. Orientar la búsqueda en entender que todo parte desde la significación que hacemos desde y sobre los objetos construidos, pretendiendo un esfuerzo en "(...) estimular la aparición de un estatuto jurídico del cuerpo que supere las contradicciones que la división entre personas y cosas ha producido en nuestra sociedad" (Espósito, 2016, p.97).

Al mirar al pasado que aún es presente, se busca reconstruir las coordenadas que mantienen a la experiencia humana dentro de la separación entre personas y cosas (Espósito, 2017). Tal rasgo definitorio se expone muchas veces como una relación esquiva $y$ selectiva con el pasado. Se constituye así en un cierto impedimento, responsable de la condición y construcción de ciertas barreras. Que se visite a los monumentos y se reciba cierta información no significa que la relación en la comunidad entre visitante-patrimonio se haya establecido; es una construcción compleja en donde la educación es una herramienta importante para dicho proceso (García Valecillo, 2009).

En los edificios patrimoniales de la ciudad de Córdoba, la relación aludida se construye en la actualidad casi exclusivamente desde un relato histórico, lo que dificulta una real apropiación con la realidad compleja que hizo y hace a la cosa construida. La experiencia durante una visita se desarrolla principalmente disgregada de la realidad espacial y física, sin la posibilidad de explorar y comprender sonidos, olores, imágenes, percepciones táctiles (Maurette, 2015; Alderoqui, 2012), lo que aísla el relato de los contenidos, a la realidad de las formas, asumiendo que, "(...) la experiencia se orienta hacia el conocimiento. La percepción, hacia el conocer" (Chillida, 2005, p.17)

La relación actual patrimonio-visitante en Córdoba, evidencia una alienación que se caracteriza tanto por la pérdida del sentimiento de identidad (suponiendo la pérdida y la capacidad de quienes habitan la ciudad de reconocerse en la memoria edificada), como por considerarse al patrimonio un tema exclusivo de y para especialistas. Las personas que habitan la ciudad no se reconocen en-y muchas veces no conocen- su patrimonio edificado. Esta característica es principalmente producto de la escisión que se da entre las decisiones asumidas sobre el patrimonio, perteneciente a toda la comunidad y la posibilidad de participar en dicho proceso, siendo extraño y aislado a la mayoría de la sociedad. El peligro se agudiza aún más al asumir al patrimonio en términos exclusivamente técnicos, ya que esto reduce a la cosa edificada solo como objeto que está ahí y que sirve para ser usado de algún modo.

El vínculo persona-objeto, sea cual fuere su carácter e intensidad, se construye en el tiempo, al interior de cada individuo y de una sociedad, de manera no siempre igual y menos aún constante ni homogénea. Si a dicha construcción se suma la condición de una discapacidad visual, se complejiza el hecho de no poder establecer un vínculo o relación visual con la cosa edificada.

Frente a la realidad y condición de las personas con discapacidad visual, nuestra contemporaneidad nos devela una exposición y sensibilidad constante hacia las imágenes, sobre todo las visuales y sonoras (Toop, 2013). Omnipresentes, continuas y penetrantes, acceden a todos los ámbitos de nuestra vida. Nuestro entorno urbano-globalizado está marcadamente modelado por una intensa imaginería programada transnacionalmente, transculturalmente (Lipovetsky y Serroy, 2015; Di Felice, 2012).

Puesto que mirar es un acto voluntario, solamente vemos aquello que miramos, "(...) lo que vemos queda a nuestro alcance" (Berger, 2005, p.15). Tocar, oler y oír algo es también otra posibilidad de mirar y percibir nuestra realidad, de situarse y de construir una relación con ello. En la actualidad, conocer es tener acceso a las representaciones, en donde la sobrestimulación continua nos enceguece las presentaciones de las cosas. Se ansían vivencias y estímulos con los que, sin embargo, “(...) uno se queda siempre igual a sí mismo" (Han, 2017, p.12) La experiencia contemporánea busca ver, oír, tocar o leer imágenes que nos remiten a lo que representan, y no ver oír o tocar las cosas mismas como realmente son (Zamora Águila, 2015); a lo que se puede replantear la necesidad de una posible pedagogía del mirar que busque "(...) una profunda y contemplativa atención y exploración" (Han, 2015, p.53)

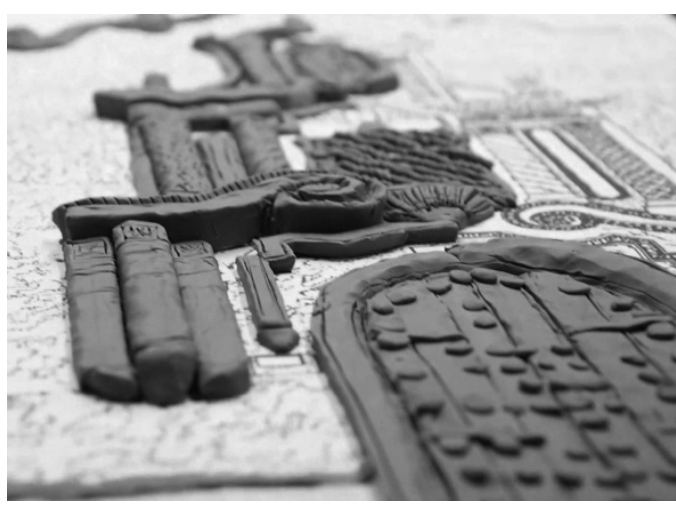

Figuras 1: maqueta háptica de la fachada utilizada en la primera experiencia de recorrido vivencial (2017).

Fuente: elaboración propia

Las personas en condición de algún tipo de discapacidad son parte de la ciudadanía y tienen, por lo tanto, e derecho a que sus necesidades como público sean consideradas. Para que una persona en condición de algún tipo de discapacidad visual acceda al conocimiento de la realidad edificada, independientemente del tipo que sea, es necesario la utilización, principalmente, del tacto como canal perceptivo junto al auditivo. Si además existe algún nivel de visión es necesario aprovecharla mediante elementos que faciliten su uso (contrastes, colores, 
macrocaracteres, etc.). Lo importante en la modalidad elegida para ser utilizada es buscar transmitir la imagen mental del objeto representado, ya sea mediante la voz, el tacto o la utilización de medios digitales.

Las adaptaciones llevadas a cabo no debieran limitarse únicamente en aspectos táctiles. Se debiera propiciar una percepción de carácter global que facilite información visual accesible y auditiva, incluyéndose también la posibilidad de agregar contenidos en soportes digitales. Muchas veces, por cuestiones relativas a la conservación del patrimonio edificado o bien por la consideración poco útil o poco significativa sobre la información, se genera la imposibilidad de garantizar una total accesibilidad al bien cultural. No obstante, siempre que sea posible, se debiera facilitar el disfrute estético que produce la experiencia espacial directa a través de tacto y del resto de los sentidos, acercando la realidad de las formas tridimensionales en su relación con la correspondiente información multisensorial accesible. En este punto es necesario asumir que, si entendemos a la accesibilidad solo como aquella posibilidad que nos permite desplazarnos por el espacio físico de manera autónoma junto a la vinculación táctil con todos sus aspectos y contenidos, la accesibilidad total como tal se vuelve una utopía.

Es importante destacar que las barreras que impiden la accesibilidad al patrimonio no siempre son de carácter físico. Existen barreras culturales construidas a partir de un desconocimiento por parte de gestores, técnicos y especialistas en conservación que trae aparejado un trato diferente hacia las personas con discapacidad, sin la posibilidad de acceder táctilmente a los contenidos expuestos cuando ello es posible. Pero también se generan barreras por falta de conocimiento en materia de accesibilidad para aquellas personas en condición de discapacidad visual por parte de responsables públicos, diseñadores, arquitectos e ingenieros.

En relación a las personas en condición de discapacidad en el año 2006 se aprueba internacionalmente la convención sobre sus derechos; ratificada por Argentina en 2008 como Ley Nacional N.o 26.378. Esta ley marca un cambio en el concepto de la discapacidad, pasando de una preocupación en materia de bienestar social a una cuestión de derechos humanos. Reconoce que las barreras y los prejuicios de la sociedad constituyen, en sí mismos, una discapacidad. De igual modo, también reconoce la importancia de la accesibilidad (en todos sus aspectos y dimensiones) al entorno físico, cultural, social y económico, a la información, la educación, la salud y las comunicaciones, para que aquellas personas en condición de discapacidad puedan gozar plenamente de todos los derechos humanos y las libertades fundamentales.

La realidad de las personas que viven condicionadas por algún tipo de discapacidad visual, representa en la actualidad universos complejos cuyo conocimiento y abordaje necesita la retroalimentación de múltiples dimensiones interdisciplinares. El acceso de las personas en condición de discapacidad visual tanto a la cultura como al patrimonio constituye un derecho reconocido en la Declaración Universal de los Derechos del Hombre, como en la propia legislación nacional argentina, por lo que las instituciones culturales debieran comenzar a adoptar las medidas que garanticen tal situación.

\section{Una primera experiencia}

Las primeras estrategias de la investigación en curso, se están desarrollando y realizando en el edificio del Colegio Nacional de Monserrat, con un grupo de personas con discapacidades visuales pertenecientes al Centro de rehabilitación para discapacitados visuales, Julián Baquero. La elección del edificio sobre el cual se realizaron las visitas se debe a que, desde el programa de investigación al que se pertenece, se lo investigó desde un planteo fenomenológico, donde se buscó estudiarlo a partir de un abordaje sobre la relación entre el edificio y las personas. No obstante, en base a estas primeras acciones se considera a futuro replicar la experiencia en otros edificios de la ciudad.

El desarrollo del trabajo propone como enfoque y acción de base una lógica de conservación activa, entendiendo a esta como el conjunto de acciones emprendidas sobre el patrimonio (dentro de un proyecto común) que tiene como objetivo el enriquecimiento de la memoria colectiva, el reconocimiento de su autenticidad y de sus valores cambiantes, y su apropiación por la comunidad (Noguera Giménez, 2002). Se asume, por lo tanto, a la conservación de una manera viva, superando la antítesis entre conciencia del pasado y proyección hacia el futuro: “(...) conservar por tanto no puede significar otra cosa que indagar en busca de una reglamentación de la transformación que, (...) reinterpreta sin destruir" (Bellini, 1999, p.12).

La primera propuesta y prueba ensayo experiencial de visita al edificio del Colegio Nacional de Monserrat se llevó a cabo el jueves 31 de agosto de 2017 con un grupo de 27 personas. Se configuró en una triangulación entre la realidad del objeto o cosa edificada, el conocimiento posible de aportar por el visitante y la problematización que el guía planteara. De esta forma la relación establecida fue el foco de la experiencia. Una relación que propició, a modo de zona de desarrollo próximo, nuevas formas de comprensión, al posibilitar nuevos interrogantes y transferencias.

La propuesta se desarrolló en carácter de Estudio-Acción (Fals Borda, 2009), como modalidad metodológica de investigación cualitativa que supone una epistemología y una perspectiva nosológica especial. Se propuso una integración entre la actividad a investigar y la acción, con el objeto de promover cambios en la estructura social y en las relaciones intergrupales, y concretar un proceso colectivo de producción de saber. Se partió de supuestos previos que orientaron el trabajo de campo en las fases iniciales, y que deberán ser reformulados a medida que se profundice el conocimiento de la realidad como la interacción junto a sus actores. 
La primera visita al edificio buscó una experiencia visual o alfabetismo visual (Mirzoeff, 2016; Mitchell, 1994) desde la implementación de la percepción háptica (Dosio, 2006; Arnheim, 1990) a partir de la asistencia de modalidades sensoriales cinestésica y táctil, a través del uso de maquetas, sonidos, recorridos, etc.

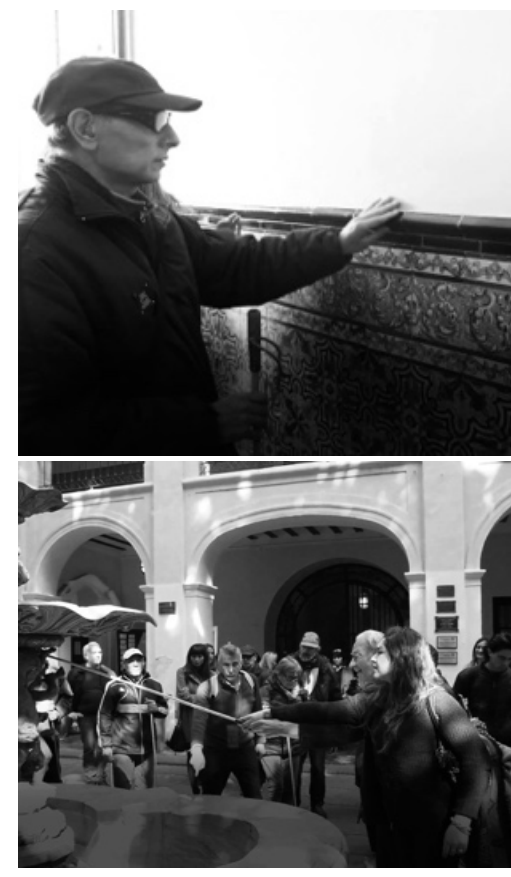

Figuras 2 y 3: recorridos sensoriales (2017) Fuente: elaboración propia.

Se posibilitó que imaginaran y comprendieran cómo es el edificio del colegio desde adentro hacia afuera y desde afuera hacia adentro. Pudieron percibir aromas, escuchar sonidos propios de un día de clases, tocar objetos con sus manos y pies, y recorrer diversos espacios interiores. La experiencia se apoyó en una charla previa junto a modelos en tres dimensiones que posibilitaron referencias para la ubicación urbana del edificio en la ciudad, el conocimiento de la totalidad del edificio en su interior y el tacto de diversos elementos del portal de ingreso.

Al final del recorrido se realizó una reflexión colectiva junto a los involucrados, y una individual en relación a las conclusiones como resultado del proceso. Quienes participaron coincidieron en sentirse partícipes por primera vez en el recorrido de un edificio de la ciudad y solicitaron se repita la experiencia en otros edificios patrimoniales de Córdoba.

Como reflexión final de la primera experiencia, se destaca que, en el acceso al patrimonio edificado por parte del colectivo de personas en condición de discapacidad visual, son de gran importancia todo tipo de adaptaciones que busquen facilitar la accesibilidad al edificio y sus espacios. En la búsqueda de construir una accesibilidad universal, es importante comenzar a repensar su generación a partir de la referencia a las necesidades específicas expresadas por dicho colectivo. Se torna necesario, por lo tanto y en primera instancia, el planteo y la garantía de proponer un adecuado y homogéneo asesoramiento a las distintas instituciones y entidades que deseen desarrollar acciones de accesibilidad al patrimonio edificado de la ciudad de Córdoba, optimizar los recursos disponibles y poder iniciar así la posible construcción de un catálogo sobre el patrimonio accesible en la ciudad.

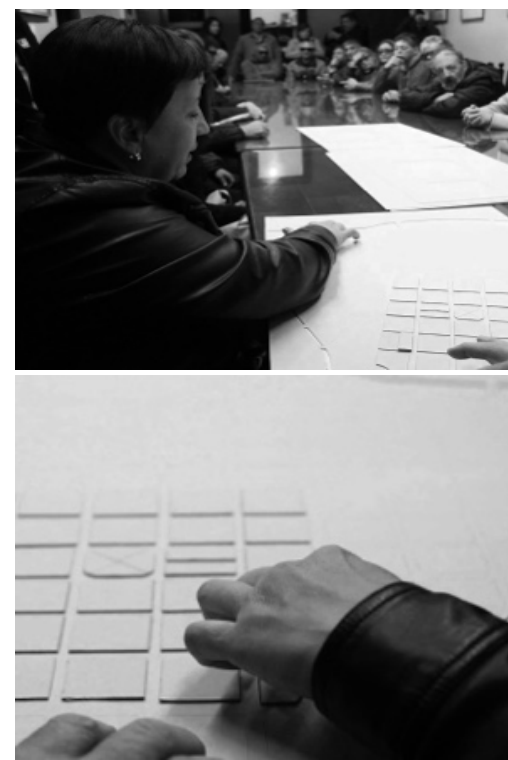

Figuras $\mathbf{4}$ y 5: maquetas sensoriales con referencias de la ubicación urbana (2017).

Fuente: elaboración propia.

Estos motivos propician imaginar la eventualidad de elaborar un documento que dé cuenta de un posible protocolo en materia de accesibilidad al patrimonio edificado para aquellas personas en condición de discapacidad visual. Debiera constituirse en un documento que busque co-construir herramientas de uso práctico para técnicos y gestores de las entidades e instituciones que decidan proponer acciones en materia de accesibilidad.

La elaboración de este documento debiera ser en primer término co-construido junto a integrantes $y$ representantes del colectivo de personas en condición de discapacidad visual. Por otra parte, debiera también dar respuesta a directrices homogéneas de actuación en materia de accesibilidad al patrimonio para así generar un documento base que intente homogeneizar las intervenciones al respecto. Sería importante que los resultados constituyeran una guía técnica base con la posibilidad futura de ser ampliada, modificada y enriquecida a partir de la ejecución de experiencias locales. Es necesario remarcar también que tal búsqueda no debiera constituirse en un recetario posible de ser aplicado a todos los proyectos. Cada bien patrimonial edificado posee ciertas particularidades que lo hacen único y que, por lo tanto, se debieran tener en cuenta como base fundamental al momento de elegir o construir acciones para su accesibilidad en una búsqueda que destaque los propios rasgos que definen, constituyen y hacen única a la realidad edificada que se propone visitar. 


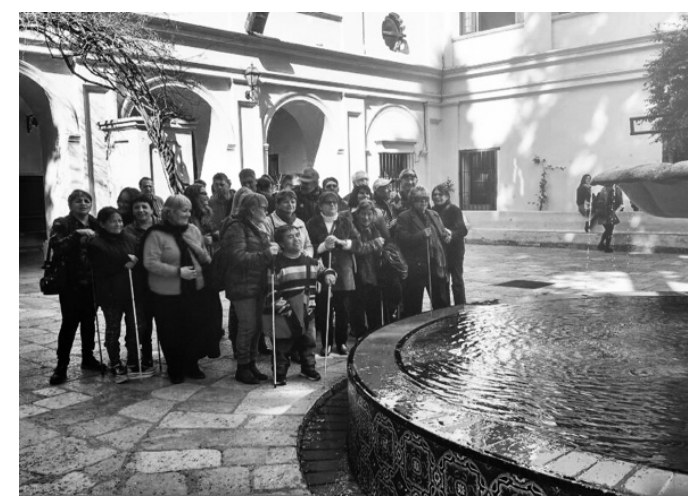

Figuras 6: Grupo de visitantes en la primera experiencia vivencial (2017)

Fuente: elaboración propia.

La experiencia de la primera visita al edificio de Colegio Nacional de Monserrat, evidenció que una de las principales dificultades que ocasiona cualquier intervención en los bienes patrimoniales frente a la búsqueda de medidas que proporcionen la accesibilidad es la de ofrecer una uniformidad a las acciones, puesto que son diversas las condiciones en relación a las discapacidades visuales. Por lo tanto, se debe afirmar y sostener que no existen soluciones únicas, ni recetas que puedan ser factibles de ser aplicadas en todas las ocasiones de forma sistemática. No obstante, algunas de las recomendaciones surgidas en la reflexión grupa final a partir de la primera experiencia son, por ejemplo, transcribir en macro-caracteres y braille la información que se ofrece (tanto cartelería como información escrita). Se suma a ello, la posibilidad de enriquecer tal información a partir de buscar brindar acceso en formato sonoro a los contenidos. En este sentido, es importante también destacar que la información que se ofrece al público, no solo debiera ser abordada a partir de descripciones visuales, sino también en una incitación que busque incluir referencias a explorar y utilizar otros sentidos. Además, es necesario el aporte de indicaciones direccionales que facilitan la movilidad espacial. Finalmente, sería importante que las instituciones inicien el desarrollo de cursos de formación a los distintos profesionales y personal que trabaja recibiendo a los visitantes, para facilitar la comunicación y atención tanto para el colectivo de personas en condición de discapacidad visual como para otros tipos de públicos en general, diversificando la oferta, y por lo tanto haciendo accesible la información del bien.

\section{Conclusión}

En la experiencia arquitectónica actual existe un predominio del lenguaje visual como herramienta exclusiva de aproximación. La experiencia profunda de vinculación y conocimiento sobre los bienes edificados no debiera surgir solo de un concepto intelectualizado, de un refinamiento compositivo ni de una imagen visual fabricada. Una experiencia arquitectónica conmovedora y reconfortante proviene de imágenes ocultas en nuestra propia historicidad como seres biológicos y culturales. Estas imágenes hacen eco de las experiencias de seguridad, confort y placer, así como de nuestra propia dialéctica con el mundo. Son imágenes que escapan a lo meramente visual y experimentan otros caminos sensoriales. La construcción de cada una de esas imágenes puede analizarse desde el punto de vista ontológico, así como desde el poder de su encuentro fenomenológico, puesto que nuestro conocimiento del mundo no solo depende de la suma de sensaciones visuales, auditivas, olfativas, táctiles, etc., sino también de las asociaciones significativas que realizamos con cada una de ellas y según una experiencia previa.

Proponer acercar la realidad del patrimonio edificado a las personas en condición de discapacidad es proponer conseguir la participación real de la sociedad en el acceso al conocimiento de nuestros bienes culturales. Todas aquellas mejoras que podamos hacer y ejecutar desde aspectos técnicos y humanos debieran ser mejoras para la totalidad de quienes habitan la ciudad en conjunto, tratando de buscar responder a cada una de las particularidades que demanden los distintos colectivos.

Aquellas intervenciones que se construyen desde una óptica de diseño universal debieran, necesariamente, incluir a toda la población. Los responsables de las instituciones alojadas en los bienes patrimoniales junto a los técnicos especialistas son quienes tendrían que proponer qué nivel de accesibilidad es factible a partir de los principios de conservación y preservación necesarios o pretendidos. No obstante, siempre se debiera velar por que se adopten las mayores medidas que propongan buscar una accesibilidad universal e integral. Las medidas desarrolladas no debieran, por lo tanto, ser la ejecución de medidas aisladas, sino más bien ser parte de un plan de accesibilidad mayor. Se torna necesario entonces tener conocimiento sobre aquello en lo que se pretende actuar, para construir mejoras mediante la búsqueda de soluciones compatibles y posibles, para evitar también modificaciones que afecten negativamente al carácter propio del bien.

Finalmente se evidencia que no solo una buena intervención física o arquitectónica sobre los monumentos logrará la conservación de nuestro patrimonio (cultural) edificado y su entorno, sino que, además, son necesarias la educación y el conocimiento.

Cómo citar este artículo/How to cite this article: Stang, J. I. y Pezza, A. (2019). Iluminando sombras Aproximaciones y experiencias para un patrimonio accesible. Estoa, Revista de la Facultad de Arquitectura y Urbanismo de la Universidad de Cuenca, 8(15), 95-101. doi:10.18537/est.v008.n015. $\mathrm{aO8}$ 


\section{Bibliografía}

- Alderoqui, S. (2012). De la relación compleja entre la educación en museos y las experiencias de los visitantes. En S. Alderoqui (Ed.), Los visitantes como patrimonio (pp. 30-39). Buenos Aires, Argentina: Universidad Nacional de Lujan. - Arnheim, R. (1990). Perceptual aspects of art for the blind. Journal of Aesthetic Education, 24 (3), 57-65.

- Bellini, A. (1999). De la restauración a la conservación; de la estética a la ética. Loggia, Arquitectura \& Restauración, (9) 10-15. doi: 10.4995/loggia. 2000.5245

- Berger, J. (2005). Modos de ver. Barcelona, España: GG.

- Chillida, E. (2005). Escritos. Madrid, España: La Fábrica.

- Coma Quintana, L. y Santacana I Mestre, J. (2010). Ciudad educadora y patrimonio. Guijón, España: Trea.

- Di Felice, M. (2012). Paisajes posurbanos. Córdoba, Argentina: Ediciones del Copista.

- Dosio, P. (2006), Apuntes sobre el arte de los no videntes. Buenos Aires, Argentina: Integrando, Fundación Artistas Discapacitados. Recuperado el día 5 de abril de 2018 de https://goo.gl/ PRFYba

- Espósito, R. (2016). Las personas y las cosas. Madrid, España: Katz.

- Espósito, R. (2017). Personas, cosas, cuerpos. Madrid, España: Trotta.

- Fals Borda, O. (2009). Una sociología sentipensante para América Latina. Bogotá, Colombia: CLACSO.

- García Valecillo, Z. (2009). ¿Cómo acercar los bienes patrimoniales a los ciudadanos? Pasos,
Revista de Turismo y Patrimonio Cultural, 7 (2), 271-280.

- Han, B-C (2015). La sociedad del cansancio. Burzaco, Argentina: Herder.

Han, B-C (2017). La expulsión de lo distinto. Burzaco, Argentina: Herder.

Liendivit, Z. (2009). La ciudad como problema estético. Buenos Aires, Argentina: Contratiempo Ediciones.

- Lipovetsky, G. y Serroy, J. (2015). La estetización del mundo. Barcelona, España: Editorial Anagrama.

- Maurette, P. (2015). El sentido olvidado. Ensayos sobre el tacto. Buenos Aires: Mardulce.

Mirzoeff, N. (2016). Cómo ver el mundo. Barcelona, España: Paidós.

Mitchell, W. J. T. (1994). Narrative, memory, and Slavery. En, M. J. M. Ezell \& K. O'Brien O'Keeffe (Ed.). Artifacts and the Production of Meaning: The Page, the Image, and the Body (pp. 199222). Ann Arbor, United States: University of Michigan Press.

- Noguera Giménez, J. F. (2002). La conservación activa del patrimonio arquitectónico. Loggia, Arquitectura \& Restauración, (13), 10-31. doi: 10.4995/loggia. 2002.3569

- Schlögel, K. (2007). En el espacio leemos el tiempo. Madrid, España: Siruela.

- Toop, D. (2013). Resonancia siniestra. Buenos Aires, Argentina: Caja Negra.

- Wagensberg, J. (2005). La rebelión de las formas. Barcelona, España: Metatemas.

- Zamora Águila, F. (2015). Filosofía de la imagen. Ciudad de México, México: UNAM. 